long-term safety. To our knowledge, this is the first long-term comparative RWD analysis of tofacitinib.

Objectives: To compare 5-year adverse event (AE) incidence rates (IRs) in patients (pts) starting tofacitinib vs biological (b)DMARDs using cohorts from the US Corrona RA registry.

Methods: This prospective, observational 5-year study embedded in the ongoing US Corrona RA registry routinely collected 9 categories of predefined AEs from participating physicians. Real-world safety event rates of major adverse cardiovascular events (MACE), serious infectious events (SIEs) and herpes zoster ( $\mathrm{HZ}$; serious and non-serious) were compared in pts with RA who started tofacitinib or a bDMARD regardless of dose/schedule between 6 Nov 2012 (US FDA approval) and 30 Jun 2017 (follow-up through 31 Dec 2017). Endpoints were selected a priori as having sufficient power to detect a 2-fold difference between cohorts at this datacut; there was insufficient power to assess malignancy. Baseline variables with a standardised difference $>|0.10|$ between tofacitinib and bDMARD initiators, and a priori selected covariates (gender, age, line of therapy, history of AE of interest) were used to construct propensity scores (PS) to derive a PS-trimmed (primary) population and a PS-matched population for sensitivity analysis (ratio: max. 4 bDMARD:1 tofacitinib; calliper=0.05). Pts were followed from initiation until an $\mathrm{AE}$ of interest, discontinuation and/or start of a new therapy +90 days, death or end of follow-up, whichever came first. Crude IRs (events/100 pt-years [PY]) were estimated; multivariable-adjusted Cox regression was used to estimate hazard ratios (HRs) comparing rates of first events between cohorts.

Results: In total, 1544 tofacitinib (2138.2 PY) and 7083 bDMARD (9904.9 PY) initiators were included. PS-trimming resulted in 1117 tofacitinib and 5542 bDMARD initiators. Rates of MACE and SIEs were similar in both cohorts (Fig 1A); adjusted HRs $(95 \%$ confidence intervals [Cls]) were: MACE $0.60(0.30,1.18)$; SIEs 0.99 (0.72, 1.36; Fig 1B). HZ IR was higher for tofacitinib vs bDMARDs (Fig 1A); HRs for $\mathrm{HZ}$ were significantly increased with tofacitinib vs bDMARDs (adjusted HR 2.12 [1.22, 3.66]; Fig 1B); all HZ events were non-serious with tofacitinib. Similar results were observed in PS-matched populations.

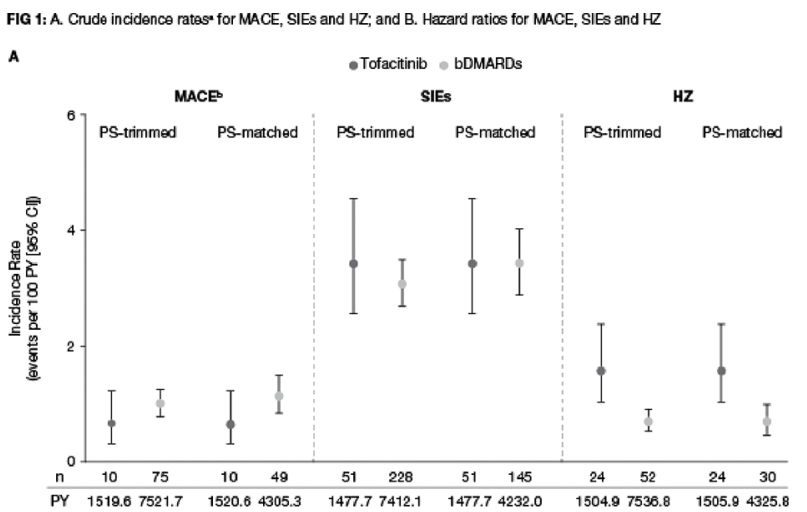

B

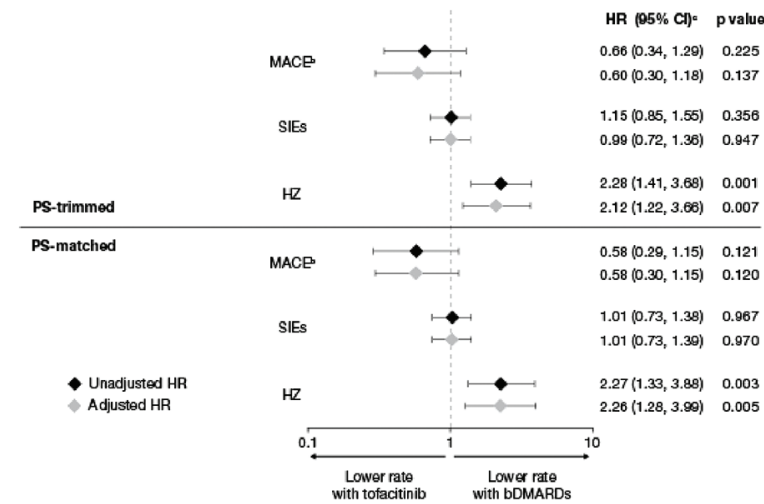

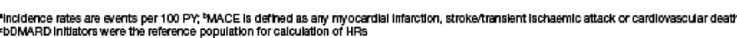

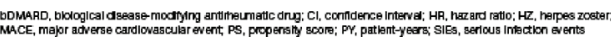

Conclusion: This is the first comparative analysis of RWD for tofacitinib and bDMARDs to use PS-trimmed and PS-matched analyses to adjust for channelling/prescribing patterns for newly approved therapies. Pts starting tofacitinib or bDMARDs for RA had similar rates of MACE and SIEs. Tofacitinib initiators had higher HZ IRs vs bDMARD initiators. These results are consistent with long-term clinical trial findings.

Acknowledgement: Sponsors: Corrona, LLC. Corrona is supported by contracted subscriptions with multiple companies. This was a Corrona/Pfizer collaboration with Pfizer financial support. Medical writing support provided by Anthony G McCluskey of CMC Connect and funded by Pfizer Inc.

Disclosure of Interests: Joel Kremer Grant/research support from: AbbVie, Genentech, Lilly, Novartis, Pfizer, Consultant for: AbbVie, Amgen, BMS, Genentech, Lilly, Regeneron, Sanofi, Pfizer, Clifton Bingham Grant/research support from: BMS, Consultant for: AbbVie, BMS, Eli Lilly, Genentech/Roche, Janssen Pfizer, Sanofi/Regeneron, Laura Cappelli Grant/research support from: BristolMyers Squibb, Consultant for: Regeneron/Sanofi Genzyme, Carol Etzel Shareholder of: Corrona, LLC, Consultant for: Merck, Employee of: Corrona, LLC, Jeffrey Greenberg Shareholder of: Corrona, LLC, Consultant for: Eli Lilly, Genentech, Janssen, Novartis, and Pfizer Inc, Employee of: Corrona, LLC, Jamie Geier Shareholder of: Pfizer Inc, Employee of: Pfizer Inc, Ann Madsen Shareholder of: Pfizer Inc, Employee of: Pfizer Inc, Connie Chen Shareholder of: Pfizer Inc, Employee of: Pfizer Inc, Alina Onofrei Employee of: Corrona, LLC, Christine Barr Shareholder of: Corrona, LLC, Employee of: Corrona, LLC, Dimitrios A Pap pas Grant/research support from: AbbVie, Consultant for: AbbVie, Employee of: Corrona, Heather J. Litman: None declared, Kimberly J Dandreo Employee of: Corrona, LLC, Andrea Shapiro Shareholder of: Pfizer Inc, Employee of: Pfizer Inc Carol A. Connell Shareholder of: Pfizer Inc, Employee of: Pfizer Inc, Arthur Kavanaugh Grant/research support from: UCB Pharma

DOI: 10.1136/annrheumdis-2019-eular.621

\section{OP0029 SWITCHING BETWEEN THE JAK1-SELECTIVE INHIBITOR-UPADACITINIB AND ADALIMUMAB FOLLOWING INITIAL NON-RESPONSE: CLINICAL AND FUNCTIONAL OUTCOMES AMONG RHEUMATOID ARTHRITIS PATIENTS}

Mark C. Genovese ${ }^{1}$, Roy Fleischmann ${ }^{2}$, Ricardo Blanco ${ }^{3}$, Stephen Hall ${ }^{4}$, Glen Thomson ${ }^{5}$, Filip van den Bosch ${ }^{6}$, Cristiano Zerbini ${ }^{7}$, Jose Jeffrey Enejosa ${ }^{8}$, LI Yihan ${ }^{8}$, Ryan Demasi ${ }^{8}$, In-Ho Song ${ }^{8} .{ }^{1}$ Stanford University, Palo Alto, United States of America; ${ }^{2}$ Metroplex Clinical Research Center and University of Texas Southwestern Medical Center, Dallas, United States of America; ${ }^{3} \mathrm{Hospital}$ Universitario Marqués de Valdecilla, Santander, Spain; ${ }^{4}$ Monash University, Cabrini Health and Emeritus Research, Malvern, Australia; ${ }^{5}$ CIADS Research, Winnipeg, Canada; ${ }^{6}$ Ghent University Hospital, Ghent, Belgium; ${ }^{7}$ Paulista Center for Clinical Research, São Paulo, Brazil; ${ }^{8}$ AbbVie, Inc., North Chicago, United States of America

Background: Initiating advanced therapy for rheumatoid arthritis (RA) patients (pts) with a bDMARD or a Janus kinase (JAK) inhibitor is recommended if remission or low disease activity (LDA) is not achieved with csDMARDs. ${ }^{1,2}$ While data show that pts are switched alternately between bDMARD and JAK treatments, there is lack of evidence for pts with inadequate response (IR) to a JAK inhibitor switching to a bDMARD. Recently, the JAK1-selective inhibitor-upadacitinib (UPA) demonstrated superior clinical and functional outcomes through 26 wks to the standard of care-adalimumab (ADA) with continued background methotrexate (MTX). ${ }^{3}$

Objectives: To describe outcomes associated with treatment switch from UPA to ADA and vice-versa among RA pts who do not achieve initial response.

Methods: This phase 3, double-blind, placebo (PBO)-controlled, head-to-head study of UPA $15 \mathrm{mg}$ q.d. vs PBO or ADA $40 \mathrm{mg}$ injection every other wk included MTX-IR patients; all pts continued stable background MTX through 26 wks. Pts without $\geq 20 \%$ improvements from bl in tender (68) and swollen (66) joint counts by wks 14,18 , or 22 were considered non-responders (NR) and switched without washout to either ADA (UPA group) or UPA (ADA group) in a bl fashion. Post-hoc analysis assessed clinical outcomes - DAS28 (CRP), CDAI, SDAI, and ACR responses (from baseline), and $\mathrm{HAQ}-\mathrm{DI}$ at 3 and 6 mos ( \pm 2 wks) post-switch Adverse events (infections) were summarized as $\mathrm{n} \%(95 \% \mathrm{Cl})$ through 6 mos post-switch (ps). Data were as observed.

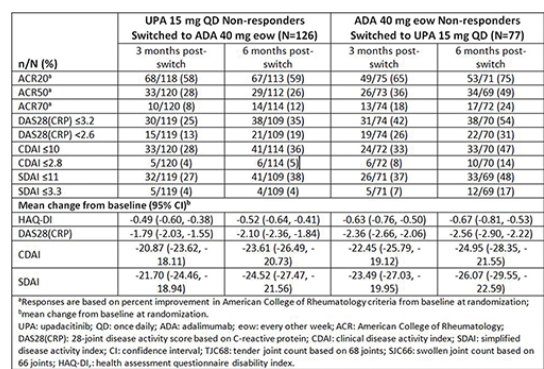


Results: Of the 651 and 327 pts randomized to receive UPA and ADA, 126 (19\%) and $77(24 \%)$, were considered NR and switched to ADA and UPA respectively. NR demographics were consistent with the overall randomized population. Of the switched pts, $90 \%$ remained in the study through 6 mo ps. Patients switched to ADA (UPA-NR) achieved 59\%/26\%/12\% improvements in ACR20/50/70 responses, and $35 \%$ achieved DAS28(CRP) $\leq 3.2$ at 6 mos ps (Table). Patients switched to UPA (ADA-NR) achieved 75\%/49\%/24\% improvements in ACR20/50/ 70 , and $54 \%$ achieved DAS28(CRP) $\leq 3.2$ at 6 mo- consistent with data observed in a phase 3 study of UPA in bDMARD-IR RA pts. ${ }^{4}$ The proportion $(95 \% \mathrm{Cl})$ of pts with infection and serious infection through 6 mos ps appeared consistent with those observed for ADA and UPA during comparable periods (ADA, switched from UPA: infection: 34.1 [26.43, 42.77], serious infection: 1.6 [0.44, 5.60]; UPA, switched from ADA: infection: 40.3 [30.02, 51.42], serious infection: 3.9 [1.33, 10.84]

Conclusion: Data from this blinded, controlled study indicate that pts with initial non-response to either UPA or ADA can benefit from switching to the other therapy. No additional safety concerns were observed. These are the first data to demonstrate effectiveness of a TNF inhibitor following failure of a JAK inhibitor.

\section{REFERENCES:}

[1] Smolen, et al. Ann Rheum Dis, 2017;76:1113-36.

[2] Singh, et al. Arthritis Rheumatol, 2016;68:1-26.

[3] Fleischmann, et al. Arthritis Rheumatol, 2018;70(Suppl 10).

[4] Genovese, et al. Lancet, 2018;391:2513-24.

Acknowledgement: AbbVie funded the study, contributed to its design, data collection, analysis, interpretation, writing, reviewing, and approval of the final version of this abstract. Medical writing support: Dalia Majumdar, PhD, and Benjamin Wolfe, PhD, of Abbvie.

Disclosure of Interests: Mark C. Genovese Grant/research support from: Sanofi/Genzyme, Genentech/Roche, RPharm, Consultant for: Sanofi/Genzyme, Genentech/Roche, RPharm, Roy Fleischmann Grant/research support from: AbbVie, Amgen, AstraZeneca, Bristol-Myers Squibb, Celtrion, Genentech, GSK, Janssen, Lilly, Novartis, Pfizer Inc, Sanofi-Aventis, UCB, Consultant for: AbbVie, Amgen, AstraZeneca, Bristol-Myers Squibb, Celtrion, Genentech, GSK, Janssen, Lilly, Novartis, Pfizer Inc, Sanofi-Aventis, UCB, Ricardo Blanco Grant/research support from: Abbvie, MSD, and Roche, Consultant for: Abbvie, Pfizer, Roche, Bristol-Myers, Janssen, Speakers bureau: Abbvie, Pfizer, Roche, Bristol-Myers, Janssen, Stephen Hall Grant/research support from: AbbVie Inc, BMS, Lilly, Janssen, Pfizer, UCB, and Novartis, Consultant for: AbbVie Inc, BMS, Lilly, Janssen, Pfizer, UCB, and Novartis, Glen Thomson Grant/research support from: AbbVie, Consultant for: Amgen, Filip van den Bosch Consultant for: AbbVie, BMS, Galapagos, Janssen, Lilly, Merck, Novartis, Pfizer and UCB, Speakers bureau: AbbVie, BMS, Janssen, Lilly, Merck, Novartis, Pfizer and UCB., Cristiano Zerbini Grant/ research support from: Amgen, Celltrion, Eli Lilly, GlaxoSmithKline, Merck, Novartis, Pfizer Inc., and Sanofi, Consultant for: Eli Lilly, Pfizer Inc., and Sanofi., Jose Jeffrey Enejosa Shareholder of: AbbVie Inc, Employee of: AbbVie Inc, Yihan Li Shareholder of: AbbVie, Employee of: AbbVie, Ryan DeMasi Shareholder of: AbbVie Inc, Employee of: AbbVie Inc, In-Ho Song Shareholder of: AbbVie Inc, Employee of: AbbVie Inc

DOI: 10.1136/annrheumdis-2019-eular.2886

\begin{tabular}{|l|l}
\hline OP0030 & RANDOMIZED CONTROLLED 24-WEEK TRIAL \\
& EVALUATING THE SAFETY AND EFFICACY OF \\
& BLINDED TAPERING VERSUS CONTINUATION OF \\
& LONG-TERM PREDNISONE (5 MG/D) IN PATIENTS \\
& WITH RHEUMATOID ARTHRITIS WHO ACHIEVED LOW \\
& DISEASE ACTIVITY OR REMISSION ON TOCILIZUMAB
\end{tabular}

Gerd Rüdiger Burmester ${ }^{1}$, Frank Buttgereit ${ }^{1}$, Corrado Bernasconi ${ }^{2}$, JoseMaria Alvaro-Gracia ${ }^{3}$, Nidia Castro ${ }^{2}$, Maxime Dougados ${ }^{4}$, Cem Gabay ${ }^{5}$, M. Jacob. van Laar ${ }^{6}$, J. Michael Nebesky ${ }^{2}$, Attila Pethoe-Schramm² ${ }^{2}$, Carlo Salvarani ${ }^{7}$, Marc Y. Donath ${ }^{8}$, Markus R. John ${ }^{2} .{ }^{1}$ Charité-Universitätsmedizin Berlin, Free University and Humboldt University of Berlin, Berlin, Germany; ${ }^{2} F$. Hoffmann-La Roche, Basel, Switzerland; ${ }^{3}$ Hospital Universitario de La Princesa IIS-IP, Madrid, Spain; ${ }^{4}$ Université Paris-Descartes, Paris, France; ${ }^{5}$ University Hospitals of Geneva, Geneva, Switzerland; ${ }^{6}$ University Medical Centre Utrecht, Utrecht, Netherlands; ${ }^{7}$ Università de Modena e Reggio Emilia, Modena, Italy; ${ }^{8}$ University Hospital Basel, Basel, Switzerland

Background: Guidelines recommend low-dose, short-term glucocorticoid (GC) treatment for rheumatoid arthritis (RA). ${ }^{1,2}$ Long-term use, especially at prednisone-equivalent doses $>5 \mathrm{mg} / \mathrm{d}$, should be avoided, ${ }^{2}$ but many patients (pts) with early established RA receive long-term GCs, often $\geq 5 \mathrm{mg} / \mathrm{d}^{3}$
Objectives: Compare GC tapering vs continuation to maintain disease control in RA pts with chronic GC exposure receiving tocilizumab (TCZ) in a randomized controlled trial.

Methods: Before randomization pts had to receive TCZ \pm conventional synthetic (cs)DMARDs and GC (prednisone-equivalent dose $5-15 \mathrm{mg} / \mathrm{d}$ ) for $\geq 24$ wks. At randomization pts had to be in at least low disease activity (LDA DAS28-ESR $\leq 3.2$ ) and receiving stable concomitant therapy (prednisone $5 \mathrm{mg} / \mathrm{d}$ [GC5mg]) and TCZ \pm csDMARDs) for $\geq 4$ wks. Pts were randomized to continue blinded GC5mg for 24 wks or undergo blinded taper (GCtaper, from $4 \mathrm{mg} / \mathrm{d}$ with 1 -mg reduction every $4 \mathrm{wks}$ to $0 \mathrm{mg} / \mathrm{d}$ at wks 16-24) while receiving stable TCZ and csDMARD doses. Pts with RA flare (DAS28-ESR $>3.2$ and increase $>0.6$ vs baseline) received open-label rescue GC5mg for 2 wks and continued blinded treatment. Primary outcome was mean change in DAS28-ESR at wk 24. Key secondary outcome was treatment success - DAS28-ESR $\leq 3.2$ at wk 24 and no RA flare during 24 wks and no adrenal insufficiency necessitating replacement therapy.

Results: 259 pts were randomized to GCtaper $(n=131)$ or GC5mg $(n=128) ; 114$ and 112, respectively, completed 24 wks. Mean baseline DAS28-ESR was 1.9 Mean RA duration was $9.2 \mathrm{y}$. For the primary endpoint, the between-arm difference was 0.6 DAS28-ESR units $(95 \% \mathrm{Cl}, 0.3,0.9 ; p<0.001$, ANCOVA) favoring GC5mg (Figure). Results were consistent for key subgroups (DAS28-ESR between-arm difference $0.5[95 \% \mathrm{Cl}-0.1,1.0]$ for TCZ monotherapy, 0.7 [0.41.0] for TCZ + csDMARDs, 0.6 [0.2-1.0] for baseline DAS28 <2, and 0.6 [0.2-1.0] for baseline DAS28 $\geq 2$ ). Most pts in both arms achieved treatment success (65\% GCtaper vs 77\% GC5mg; relative risk, 0.83 [0.71-0.97]; $p=0.021$, Cochran-Mantel-Haenszel test); $11 \%$ of GC5mg pts and $26 \%$ of GCtaper pts experienced RA flare. One GC5mg pt and no GCtaper pts discontinued blinded treatment due to insufficient flare control. Serious adverse events (no deaths) were reported for $5 \%$ of GC5mg vs $3 \%$ of GCtaper pts. No pts had symptomatic adrenal insufficiency.

Conclusion: Continued GC5mg provided better DAS28-ESR control than GC taper in RA pts in LDA or remission. The 0.6 DAS28-ESR unit between-arm difference should be interpreted in the context of approximately two-thirds of tapered pts experiencing treatment success and no tapered pts discontinuing due to lack of flare control. The taper schedule was safe regarding adrenal insufficiency. The results suggest that all pts achieving LDA or remission with TCZ and receiving long-term low-dose GC should be considered for GC tapering, ideally targeting discontinuation.

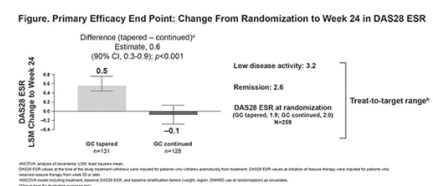

REFERENCES:

[1] Singh JA et al. Arthritis Rheum. 2016;68:1.

[2] Smolen JS et al. Ann Rheum Dis. 2017;76:960.

[3] Buttgereit F, Bijlsma JW. Ann Rheum Dis. 2017;76:1785.

Disclosure of Interests: Gerd Rüdiger Burmester Consultant for: Roche, Sanofi-Genzyme, Speakers bureau: Roche, Sanofi-Genzyme, Frank Buttgereit: None declared, Corrado Bernasconi Consultant for: Roche, Jose-Maria Alvaro-Gracia Consultant for: AbbVie, Bristol-Myers Squibb, Eli Lilly, MSD, Novartis, Pfizer Inc, Roche, Sanofi, and UCB, Speakers bureau: AbbVie Bristol-Myers Squibb, Eli Lilly, MSD, Novartis, Pfizer Inc, Roche, Sanofi, and UCB, Nidia Castro Shareholder of: F. Hoffmann-La Roche, Employee of: F. Hoffmann-La Roche, maxime dougados Grant/research support from: Eli Lilly and Company, Pfizer, AbbVie, and UCB Pharma, Consultant for: Eli Lilly and Company, Pfizer, AbbVie, and UCB Pharma, Cem Gabay Grant/research support from: Roche, Pfizer, AB2 Bio Ltd, Consultant for: Roche, Pfizer, Lilly, AbbVie, Sanofi, Regeneron, Bristol-Myers Squibb, Novartis, UCB, AB2 Bio Ltd, Debiopharm, Jacob M. van Laar Grant/research support from: Genentech, Consultant for: F. Hoffmann-La Roche, J. Michael Nebesky Share holder of: F. Hoffmann-La Roche, Employee of: F. Hoffmann-La Roche, Attila Pethoe-Schramm Shareholder of: F. Hoffmann-La Roche, Employee of: $F$ Hoffmann-La Roche, Carlo Salvarani: None declared, Marc Y. Donath Consultant for: Roche, Markus R. John Shareholder of: Roche, Employee of: Roche

DOI: 10.1136/annrheumdis-2019-eular.2883 